NOTAS

\title{
LA ANERKENNUNG HEGELIANA. UNA LECTURA HERMENÉUTICA DEL RECONOCIMIENTO
} Eduardo Charpenel*

\begin{abstract}
RESUMEN: Este artículo analiza la interpretación de Ricoeur sobre el concepto de Anerkennung en la filosofía temprana de Hegel. Se discute la importancia primordial de este concepto y se evalúa el significado del mismo dentro de un orden ético y político.
\end{abstract}

PALABRAS ClaVE: Ricoeur, Hegel, Anerkennung.
ABSTRACT: This article analyzes Ricoeur's interpretation of Hegel's Anerkennung (Recognition) in his early philosophical thought. The paramount importance of this notion is discussed and its meaning is analyzed in an ethical and political order.

KEYwORDS: Ricoeur, Hegel, Anerkennung (Recognition).

RECEPCIÓN: 01 de junio de 2009.

ACEPTACIÓN: 21 de enero de 2010.

\footnotetext{
* Universidad Panamericana.
} 


\section{LA ANERKENNUNG HEGELIANA. UNA LECTURA HERMENÉUTICA DEL RECONOCIMIENTO}

En el camino hermenéutico trazado por Paul Ricoeur en su análisis del reconocimiento, uno de los interlocutores más importantes es, sin lugar a dudas, G. W. F. Hegel, quien aparece en un momento destacado de su discusión sobre este tema. En el capítulo intitulado "Hegel en Jena: Anerkennung", de su obra intitulada Caminos del reconocimiento, Ricoeur acomete el estudio del reconocimiento en su desarrollo "total", tal y como Hegel lo esboza en sus escritos de juventud y que culmina con su Fenomenología del espiritu. La reflexión hegeliana es total en la medida que pretende mostrar la realidad de "el vínculo entre auto-reflexión y orientación hacia el otro". ${ }^{1}$ El proyecto

${ }^{1}$ Paul Ricoeur, Caminos del reconocimiento, 2006, México, FCE, trad. Agustín Neira, p. 219. filosófico hegeliano -en consonancia con los otros proyectos filosóficos idealistas del siglo XIX-se plantea a sí mismo como un intento de superar las antinomias irresolubles a las que el pensamiento kantiano habría supuestamente conducido. Noúmeno y fenómeno, libertad y naturaleza, conciencia y mundo, son tan sólo algunas de las fracturas que Hegel pretende reunificar, mediante el pensamiento especulativo y dialéctico, toda vez que éste pone de manifiesto figuras contingentes que el Espíritu encarna en su tránsito progresivo a través de la historia.

Ricoeur, permaneciendo fiel a los principios de su propia hermenéutica, se esfuerza por rescatar la intersubjetividad que esta dialéctica supone. Ya 
desde su concepción hegeliana, el reconocimiento sólo puede ser objeto de reflexión filosófica si éste es congruente con nuestra particular forma de conocer el mundo y con nuestras apreciaciones éticas más fundamentales. Ricoeur comparte esta preocupación, pues ambas dimensiones, tanto la epistemológica como la moral, son inseparables una de la otra cuando se aborda esta materia. A continuación, veremos cómo Ricoeur, en el curso de su análisis sobre Hegel, pondrá de relieve ciertas cuestiones cuya importancia resulta determinante en muchos sentidos.

De acuerdo con Hegel, la dinámica del proceso del reconocimiento va siempre acompañada de un movimiento de un polo negativo hacia uno positivo. En ningún lado parece quedar esto tan claro como en la Fenomenología del espíritu, donde la conciencia desgarrada sólo puede sustraerse de su condición después de haber visto enajenada su propia libertad. En otros términos, podría decirse que la importancia de la libertad sólo puede ser valorada en todas sus dimensiones cuando los individuos han experimentado o han contemplado condiciones en las que ésta se ha visto coaccionada. Nada tan ilustrativo a este respecto como el análisis de la dialéctica entre amo y esclavo. A diferencia de Nietzsche, por ejemplo, Hegel no consideraba que el amo permanecie- ra siempre amo y que el esclavo permaneciera siempre esclavo. Todo lo contrario: la importancia que le da el esclavo a su libertad paulatinamente se modifica y esto lo conduce a luchar por el reconocimiento que le ha sido despojado. La historia, a juicio de Hegel, comprueba esta aseveración, pues los cambios de poder en las estructuras sociales y políticas van siempre acompañados de la exigencia de que ciertos derechos, antes alienados, se vean respetados en el presente. Esto no sólo parece ser cierto en el terreno de los cambios globales de una sociedad, sino que a nivel individual, una persona valora más la libertad si ha colaborado de manera efectiva en su consecución.

Así pues, la "negatividad", el momento inicial de desigualdad que busca ser superado por los individuos, resulta ser una especie de motor que guía la historia en busca de la instauración plena del reconocimiento moral. Sin embargo, a diferencia de Hobbes, Hegel no piensa que el proceso del reconocimiento se elimine apelando a una instancia artificial como la que el filósofo inglés describe en su Leviatán, según la cual el reconocimiento se logra cuando los individuos en estado de naturaleza otorgan voluntariamente su poder a un Estado vigilante. La Sittlichkeit, la vida ética por antonomasia, sólo toma forma mediante el recorrido 
NOTAS

por configuraciones mutables, las cuales, dice Ricoeur, "son compromisos históricos entre exigencias especulativas y la experiencia empírica". ${ }^{2}$ Esto quiere decir que el pensamiento filosófico, en un período histórico determinado, bien puede concebir ciertos principios o teorías más justas, pero esto no implica necesariamente que la especulación conduzca a un reconocimiento inmediato de las condiciones vigentes en una comunidad: piénsese, por ejemplo, el caso de Aristóteles, quien llega a concebir los lineamientos fundamentales de la justicia equitativa $y$, a su vez, adopta la posición esclavista dominante en su época, y restringe la participación en la vida política a un número selecto de ciudadanos. ${ }^{3}$ Cada conquista institucional, "corresponde a una amenaza negativa específica", ${ }^{4}$ lo cual deja ver precisamente cómo, en nuestra situación histórica particular, somos mucho más conscientes de lo injusto que de lo propiamente justo. Por usar una expresión de cuño fenomenológico, podríamos decir que la conciencia de lo justo se integra a nuestro "mundo de la vida" de una forma prácticamente imperceptible para nosotros, mientras que lo injusto nos parece, de forma evidente, una alienación que nos vemos compelidos a superar

${ }^{2}$ Paul Ricoeur, op. cit., p. 220.

${ }^{3}$ Aristóteles, Política, 1998, Madrid, Gredos, trad. Manuela García Valdés, 1253b ss.

${ }^{4}$ Paul Ricoeur, ibidem. de alguna forma u otra. A la luz de esto, se puede apreciar nítidamente por qué la indignación es un sentimiento clave dentro de una política del reconocimiento. Deploramos sobremanera todo aquello que impide el reconocimiento al que legítimamente aspiran los demás seres racionales. En este ámbito, como confirma Ricoeur, nos hemos desplazado del reconocimiento activo a uno pasivo. En otras palabras, es un "ser reconocido por otro" lo que define propiamente la dialéctica de la negatividad y de la institucionalización caracterizada por Hegel.

Ricoeur se aboca al estudio de los escritos de juventud de Hegel precisamente para destacar aspectos importantes de la génesis del pensamiento del filósofo alemán. Como ya hemos visto, la formulación hegeliana del reconocimiento bien puede entenderse como una respuesta a Hobbes, pero también debe interpretarse como un marcado distanciamiento de Kant, quien - a juicio de los idealistas posteriores-consideró la autonomía moral de forma absolutamente independiente de la inserción de los sujetos en contextos históricos específicos. ${ }^{5}$

${ }^{5}$ Véase a este respecto la síntesis que presenta Habermas de las críticas hegelianas a Kant. Los puntos fundamentales que aborda son el formalismo, el universalismo abstracto, la impotencia del simple deber y la insuficiencia de la intención. Cfr. Jürgen Habermas, “¿Afectan las objeciones de Hegel a Kant también a la ética del discurso?", Escritos sobre moralidad y eticidad, 2004, Barcelona, Paidós, trad. Manuel Jiménez Redondo, p. 97-9. En lo particular, 
Esa escisión-tan característica de la modernidad-es un problema al que los antiguos griegos no se enfrentaron: el modelo clásico de la polis suponía una "unidad viva entre la libertad individual y la libertad universal". ${ }^{6}$ Como bien observaba el mismo Aristóteles, la polis garantizaba que las excelencias individuales fuesen desarrolladas mediante la adopción de las costumbres de los ciudadanos virtuosos. Por el hecho mismo de vivir en una comunidad, las concepciones de lo "bueno" y lo "malo" no eran concebidas como aisladas, sino como percepciones comunes que los ciudadanos poseían. ${ }^{7}$ Ricoeur señala, no obstante, que este aristotelismo inicial de Hegel no permanece incólume, sino que se ve ampliado por una "concepción claramente idealista que asigna a la conciencia la capacidad de generar las fases sucesivas de autodiferenciación acompasadas por la lucha por el reconocimiento". ${ }^{8}$ Esta transición sólo es posible, a juicio de Ricoeur, por la enorme deuda de Hegel con Fichte

\footnotetext{
yo disiento de las críticas contra la filosofía expuestas en este escrito, pero no me detendré en este artículo a revisar dicha temática.

${ }^{6}$ Paul Ricoeur, op. cit., p. 223.

${ }^{7}$ A este respecto el siguiente pasaje es ilustrativo: "Y esto es lo propio del hombre frente a los demás animales: poseer, él sólo, el sentido del bien y del mal, de lo justo y de lo injusto, y de los demás valores, y la participación comunitaria de estas cosas constituye la casa y la ciudad", Aristóteles, Política, 1253a 12-13. El subrayado es mío.

${ }^{8}$ Paul Ricoeur, ibidem.
}

y con su interpretación del derecho natural. Es la filosofía de Fichte lo que en última instancia le permitirá a Hegel tematizar la lucha por el reconocimiento e introducir en la dialéctica entre autoaserción e intersubjetividad.

Ricoeur se aboca al estudio de un fragmento muy significativo de los años de juventud de Hegel, titulado System der Sittlichkeit, uno de los primeros esbozos que Hegel hizo de su sistema. Si bien hay muchas ideas en ese pequeño opúsculo que Hegel refinará, no deja de ser sintomático el que ahí se trate el problema del reconocimiento en función de categorías como "Identidad" y "Totalidad", por un lado, y de "Indiferencia" y "Universalidad", por el otro. Leamos el fragmento de juventud de Hegel:

Por eso el reconocimiento del individuo en cuanto viviente -tal es el reconocimiento de la persona- es el reconocimiento del otro como "concepto absoluto", "ser libre", "posibilidad de ser el contrario de sí mismo respecto a una determineidad", pero es un reconocimiento aún formal al que le falta el momento de la diferencia. Es este momento el introducido por la relación de dominio y de servidumbre, potencia más alta del reconocimiento por ser real, mientras que la precedente sólo es ideal y formal. ${ }^{9}$

\footnotetext{
${ }^{9}$ Cfr. Paul Ricoeur, op. cit., p. 227.
} 
NOTAS

Como bien nos advierte Ricoeur, la instancia aquí descrita por el filósofo alemán dista todavía mucho de ser la de la vida del espíritu. El fragmento ha de leerse más bien en términos de las distintas potencias o pulsiones que determinan la intersubjetividad en un estado próximo al de naturaleza. En principio, como aquí se nos dice, somos capaces de atribuir una dignidad universal a todos los seres humanos. El contacto con el otro, al menos como lo describe Hegel, implica un primer momento en el cual podemos atribuir a los otros individuos un estatuto idéntico al nuestro. Sin embargo, ese momento abstracto de reconocimiento no permanece por mucho tiempo, ya que en nuestro trato con las personas nos percatamos de las "diferencias" que son ajenas a lo teorético, pero propias de lo real. En el terreno de lo especulativo, el hombre es capaz de llegar a una unidad del concepto sólida, que es consistente dentro de los límites de ese mismo ámbito, pero ésta es reconfigurada por nuestra inserción en un contexto social específico donde aparecen las fuerzas de poder y dominio. Este proceso de ninguna manera implica que uno acepte despóticamente estas diferencias o pretenda perpetuarlas, sino simplemente nos hace reconocer la alteridad a la que tarde o temprano se enfrenta una posición especulativa desligada de lo concreto.
Precisamente porque el reconocimiento no termina ahí, existe otro momento al que llama Hegel la "indiferencia de las potencias precedentes", donde se establece una jerarquía entre las distintas necesidades o preferencias que tiene el hombre (Ricoeur menciona, entre otras, el trabajo, la diferente entre deseo y goce, y la articulación del trabajo con forma de posesión), las cuales se retrotraen nuevamente a un terreno especulativo donde se les juzga en términos de totalidad. Como dice Hegel: "la segunda relación constitutiva se integra en la universalidad, en el concepto de la primera". ${ }^{10}$

En este sentido, otra vez, se vuelve a encontrar una divergencia de enfoque con respecto a Hobbes, pues las potencias de las que el filósofo inglés habla para la gestación de la vida en comunidad sólo hacen referencia a la muerte, a la trasgresión de los derechos y a la violencia. No se debe pensar, por supuesto, que Hegel se mantiene indiferente ante cuestiones de esta índole. Lo que se integra a la universalidad no sólo tiene un carácter positivo: también los aspectos negativos de la vida intersubjetiva se incluyen en el reconocimiento para evaluar el mayor número de posibilidades de la acción social y política, y reflejar éstas en el contrato que funda al Estado. Hegel nos dice que en este tránsito que se da entre

\footnotetext{
${ }^{10}$ Paul Ricoeur, op. cit., p. 225.
} 
la diferencia de lo particular y la identidad del concepto universal, sería imposible que no existieran ciertas capacidades del ser humano que fueran ampliadas o extendidas a otros sectores, en virtud del reconocimiento político. Esto no desdice lo que se dijo sobre la negatividad, la cual, efectivamente, echa a andar el proceso del reconocimiento mutuo. Lo que aquí se afirma, más bien, es que ese proceso no parte de cero. El proceso parte de lo dado por las potencias esencialmente positivas que otorga la naturaleza.

Por otro lado, es evidente que el reconocimiento político y social viene a transformar radicalmente la vida como es dada en el estado de naturaleza. Pero la manera en que esto sucede, para Hegel no es inmediata, sino que forma necesariamente parte de un desarrollo continuado en el cual, comúnmente, se llega a "negar la realidad de un viviente en su determineidad", ${ }^{11}$ que siembra ciertas actitudes y disposiciones en los actores sociales, que los inducen a depurar y refinar el proceso del reconocimiento. Es evidente que puede haber retrocesos, pero no menos evidente es el hecho de que el progreso moral puede llegar a concretarse y a consolidarse efectivamente en un núcleo social. Hegel nos hace ver con esto que es muy difícil que los hombres se despren-

\footnotetext{
${ }^{11}$ Cfr. Paul Ricoeur, op. cit., p. 226.
}

dan de los principios donde ven reflejados la expresión de su voluntad y en los cuales se expresan sus derechos $\mathrm{y}$ obligaciones fundamentales.

A través del Trieb y del estamento de la familia se llega al pueblo (Volk), el cual es, para Hegel, el único portador de la vida ética absoluta. El reconocimiento que se da en el pueblo no ha perdido todo el dinamismo de las anteriores etapas. Todo lo contrario: se transita del momento en el que se establece una constitución a otro momento en el cual se ejerce y se pone en práctica aquello que los individuos han elegido como normas y principios autónomos. No se trata de la conformación indiferente de un sistema especulativo y estático. Valiéndonos de una terminología hermenéutica, podemos decir que hay un reconocimiento en la aplicación (applicatio o Anwendung, como Gadamer la llama) de los principios. ${ }^{12}$ No es el mismo proceso el que se da en la legislación que en el ejercicio concreto de los principios que han de regir la vida en comunidad. Sólo en este marco se pueden apreciar con nitidez las relaciones mutuas de una sociedad, así como las instancias donde la praxis distorsiona el orden social.

Hay, pues, dos momentos centrales en la jerarquía de potencias descri-

${ }^{12} \mathrm{Cfr}$. Hans-Georg Gadamer, Verdad y método, 2003, Salamanca, Sígueme, trad. Ana Agud Aparicio y Rafael de Agapito, p. 378 ss. 
NOTAS

tas por Hegel: la formalidad del derecho y la estructura del ejercicio político en el marco de la justicia. El vaivén continúo entre un momento y otro se ve siempre amenazado por el crimen, es decir, por acciones particulares que quebrantan el orden deseado por los ciudadanos. Por ello, también en sentido estricto, nunca se puede evocar el reconocimiento social sin mencionar este contrapunto que lo amenaza.

Justo en este momento de la discusión Ricoeur modifica el tono de su exposición y apunta una crítica en contra de Hegel, la cual hace eco de su obra Del texto a la acción, donde discute dificultades semejantes en los planteamientos del filósofo alemán. El filósofo francés señala, en tan sólo unas breves líneas, un problema serio en el hegelianismo: la referencia especulativa en torno a la "totalidad" y a la "identidad" sin contrapartida empírica. El proyecto filosófico hegeliano asume una ontoteología que impide, según nos dice Ricoeur, "que la pluralidad humana aparezca como la referencia insuperable de las relaciones de mutualidad". ${ }^{13}$ Lo cual, dicho sea de paso, es perfectamente congruente con su posición ya antes esbozada: "si un hombre o un grupo de hombres, un partido, se arroga el monopolio del saber de la práctica, se arrogará también el derecho de hacer el bien de los

${ }^{13}$ Paul Ricoeur, op. cit., p. 220. hombres a pesar de ellos". ${ }^{14}$ El peligro de esto, de acuerdo con Ricoeur, es que el Estado, sea como sea que estuviese conformado, se ufanaría de ser la única instancia que pudiese regir la vida ética, impidiendo así que los individuos puedan juzgar críticamente aquello que la generalidad legisla por encima de ellos. Como nos dice el hermeneuta francés, en un tono sumamente aristotélico, no se puede correr el riesgo de postular un conocimiento tan apodíctico de los asuntos humanos, pues se desatiende del carácter particular, peculiar y contingente de las interacciones entre los miembros concretos de una sociedad específica. $^{15}$

Posteriormente, Ricoeur analiza otro opúsculo de juventud de Hegel, el cual se titula Realpolitik. La discusión del mismo se vuelve pertinente toda vez que en estos escritos también encontramos una respuesta a Hobbes. Aquí, sin embargo, la naturaleza apa-

${ }^{14}$ Paul Ricoeur, "La razón práctica", Del texto a la acción, 2001, México, FCE, trad. Pablo Corona, p. 237.

${ }^{15}$ Suponer lo contrario implica efectuar una violencia contra la misma razón práctica. "Es necesario volver a decir con Aristóteles que no hay saber sino de las cosas necesarias e inmutables. Por lo tanto, la razón práctica no debe elevar sus pretensiones más allá de la zona media que se extiende entre la ciencia de las cosas inmutables y necesarias y las opiniones arbitrarias, tanto de las colectividades como de los individuos. El reconocimiento de este estatuto medio de la razón práctica es la garantía de su sobriedad y de su apertura a la discusión y a la crítica." Paul Ricoeur, ibidem. 
rece como lo suprimido, pues Hegel ya muestra aquí una preocupación más franca por delimitar la realidad del Espíritu que en su escritor anterior. El retorno del Espíritu a su ipseidad, constituye, a juicio de Ricoeur, una propuesta del filósofo alemán que pretende encontrar una motivación moral genuina en el seno del reconocimiento. Éste es, pues, un reconocimiento de una índole metafísica muy particular: el Espíritu se reconoce después de que se ha hecho otro a sí mismo y vuelve a su esencia con una concepción distinta de sí. A Ricoeur le interesa subrayar las tres partes de las que está compuesta esta obra. Una presentación esquemática facilitará la comprensión:

1. Concepto del espíritu: Hegel describe, en principio, una psicología de la inteligencia y la voluntad. El reconocimiento aquí se da en términos del recorrido de la voluntad -en posesión el yo de sí-, de aquello que es externo a él y la configuración de lo ajeno en función de las motivaciones particulares. Encontramos de nuevo aquí la insatisfacción de las necesidades y el establecimiento de una jerarquía de valores morales. El reconocimiento sobreviene con las relaciones del derecho, el cual se entiende como recíproco y autónomo en momentos como el estado de naturaleza, el ordenamiento jurídico y la conformación políti- ca. Hegel pretende mostrar, a lo largo de este tránsito, la forma necesaria en que se expresa el reconocimiento en cada una de estas etapas. El orden especulativo y conceptual es también muy importante para fijar la mutualidad. El derecho, igualmente, busca restaurar la asimetría de las relaciones humanas.

2. Espiritu efectivo: esta segunda parte del opúsculo hegeliano deja de lado la abstracción de la inteligencia y la voluntad. Del reconocimiento propio se pasa al "ser-reconocido" universal. Aquí sucede algo muy parecido que lo ya descrito por Hegel en su System der Sittlichkeit, pero las facultades que impulsan este proceso son ahora distintas. Este momento, por otra parte, hace "coincidir, en el ser reconocido, la voluntad de lo singular y la voluntad común". ${ }^{16}$ Cuando hay una trasgresión, la persona y no la "cosa" (Sache) se ve afectada, y la ley tiene ya el poder de reconocer la calidad moral del sujeto que padece injusticia. El derecho puede, en esta instancia, dar paso a la ley de los individuos autónomos.

3. Constitución: en este momento constitutivo, parecería que el reconocimiento ya no tendría cabida, pero éste tiene un papel fundamental todavía en "el soporte jerárquico entre voluntad considerada como universal y

${ }^{16}$ Paul Ricoeur, Caminos del reconocimiento, op. cit., p. 233. 
NOTAS

voluntad particular". ${ }^{17}$ Hay un momento maquiavélico en donde el Estado es constituido y el orden tiene que ser implantando, incluso a costa de cierto ejercicio despótico de la violencia. Esto garantiza el obedecimiento a la ley, tan distinta a la alegre felicidad griega, que supone otorgarle a un poder superior potestades distintas a las de los individuos, considerados cada uno de forma aislada. El espíritu "produce ahora otro mundo, un mundo que tiene un rostro de sí mismo; en él su obra está en el interior de sí, y en el que accede a la intuición de sí como sí". ${ }^{18}$ Cuando de esta instancia se parta a una especulación teológica de la forma en que éste y el Estado se relacionan, el lenguaje pasará no tanto a ser el del reconocimiento sino el de la reconciliación.

Como conclusión de este recorrido, podemos afirmar que la libertad concebida por Hegel no se conforma con la inmediatez del ser en-sí abstracto de la razón, sino que llega a la realidad del otro. El reconocimiento de la mutualidad no se gana a espalda de los otros individuos, sino que se gana gradualmente en virtud de los demás. La Anerkennung hegeliana no es un intento de escapar a la alteridad sino, por el contrario, una forma de hacer partícipe de la libertad al

${ }^{17}$ Paul Ricoeur, ibidem.

${ }^{18}$ Paul Ricoeur, ibidem. mayor número de personas posibles. La plena instauración de categorías como autonomía y dignidad en un orden social es un trabajo fundamentalmente histórico que nos compele a todos. Nuestro propio momento histórico nos presenta exigencias a las que nos vemos comprometidos y que no podemos desatender, si es que deseamos que este reconocimiento moral se extienda. La intención de este proyecto moral y político concuerda con las intenciones de Ricoeur, como se puede apreciar cuando este último manifiesta su afinidad con la idea hegeliana de que:

el bien del hombre y la función del hombre no están preservados de la dispersión en técnicas y artes particulares, sino en la medida que la propia política es un saber arquitectónico, es decir, un saber que coordina el bien del individuo con el de la comunidad y que integra las competencias particulares en una sabiduría relativa al todo de la Ciudad. ${ }^{19}$

Sin embargo, por más tentativa que resulte esta arquitectónica, el carácter necesario y objetivo de la misma debe impedirnos, desde una perspectiva fiel a la hermenéutica, concebir un momento en el que el reconocimiento sea comprendido unívocamente y desligado de las capacidades de atestación e innovación propias del ser humano.

${ }^{19}$ Paul Ricoeur, "La razón práctica", Del texto a la acción, op. cit., p. 234. 